\title{
The novel estrogen-induced gene EIG121 regulates autophagy and promotes cell survival under stress
}

\author{
L Deng', J Feng' and RR Broaddus, ${ }^{*}$
}

We previously identified a novel estrogen-induced gene, EIG121, as being differentially regulated in endometrioid and nonendometrioid endometrial carcinoma. The function of EIG121 was unknown. Using a tetracycline-inducible system, we found that overexpression of EIG121, but not of LacZ, caused a profound suppression of cell growth. Subcellular fractionation and immunofluroscent labeling indicated that EIG121 was a transmembrane protein localized in the plasma membrane-late endosome-lysosome compartments. Deletion of the putative transmembrane domain abolished the membrane association. In cells overexpressing EIG121, cytoplasmic vacuoles accumulated after EIG121 induction, and the autophagosome marker LC3 translocated into punctuate, dot-like structures. Electron microscopy revealed that in cells overexpressing EIG121, autophagosomes were markedly increased. Overexpression of EIG121 also increased the cells containing acidic vesicles and induced lysosomal degradation of long-lived proteins. In MCF-7 cells, both EIG121 and LC3 were rapidly degraded by a lysosomal mechanism after starvation. Knockdown of EIG121 blocked starvation-induced LC3 degradation. By itself, knockdown of EIG121 did not affect cell survival. When combined with starvation or cytotoxic agents, EIG121 knockdown greatly increased apoptosis. Our results suggest that EIG121 is associated with the endosome-lysosome compartments and may have an important role in autophagy. Under unfavorable conditions such as starvation and exposure to cytotoxic agents, EIG121 may protect cells from cell death by upregulating the autophagy pathway.

Cell Death and Disease (2010) 1, e32; doi:10.1038/cddis.2010.9; published online 1 April 2010

Subject Category: Cancer

This is an open-access article distributed under the terms of the Creative Commons Attribution License, which permits distribution and reproduction in any medium, provided the original author and source are credited. This license does not permit commercial exploitation without specific permission.

Using a cDNA microarray screening technique, we previously reported the identification of a novel estrogen-induced gene EIG121. ${ }^{1}$ EIG121 was overexpressed in endometrial hyperplasia and endometrioid-type endometrial carcinoma, two pathological endometrial proliferations associated with unopposed estrogen exposure. In contrast, EIG121 was profoundly suppressed in uterine papillary serous carcinoma (UPSC) and malignant mixed mullerian tumor (MMMT), nonendometrioid endometrial carcinomas that are largely independent of estrogen exposure and associated with adverse clinical outcomes. In agreement with our observations, some recent gene expression profiling studies of endometrial cancer also found that EIG121 (KIAA1324) showed the greatest difference in levels of gene expression between endometrioid carcinoma and UPSC and MMMT. ${ }^{2}$ These intriguing findings have suggested to us that EIG121 may have very different roles in the development of earlystage endometroid endometrial carcinoma compared with the progression of more advanced endometrioid or nonendometrioid carcinomas.

The cellular function of EIG121 is completely unknown, making the effective study of its role in cancer impractical.
Using a BLAST search, the human EIG121 gene is mapped to chromosome 1p13.1. Intriguingly, its expression is highly conserved across species during evolution. Human and rodent proteins are $90 \%$ identical. The sequence for mammalian EIG121 is very similar to that of genes of unknown function in C. elegans, Xenopus, fish, and chicken. Such homology across species suggests that EIG121 has an important cellular function. We thus used strategies of overexpression and RNAi to study the role of EIG121 in cell death and growth. To our surprise, EIG121 overexpression suppressed cell growth and induced autophagy, a degradative and recycling mechanism for the removal and turnover of bulk cytoplasmic components. Using EIG121 siRNA, we demonstrated that EIG121-induced autophagy promoted cell survival after nutrient deprivation and exposure to cytotoxic chemotherapeutic agents.

\section{Results}

Overexpression of EIG121 leads to inhibition of cell growth and apoptosis. We previously observed

\footnotetext{
${ }^{1}$ Department of Pathology, University of Texas M.D. Anderson Cancer Center, Houston, TX 77030, USA

*Corresponding author: RR Broaddus, Department of Pathology, Box 85, University of Texas M.D. Anderson Cancer Center, 1515 Holcombe Blvd., Houston, TX 77030 , USA. Tel: + 713745 2794; Fax: + 713792 5532; E-mail: rbroaddus@mdanderson.org

Keywords: EIG121; autophagy; lysosome; starvation; apoptosis; cell survival

Abbreviations: UPSC, uterine papillary serous carcinoma; MMMT, malignant mixed mullerian tumor; TGN, trans-Golgi network

Received 26.11.09; revised 11.2.10; accepted 18.2.10; Edited by D Bano
} 


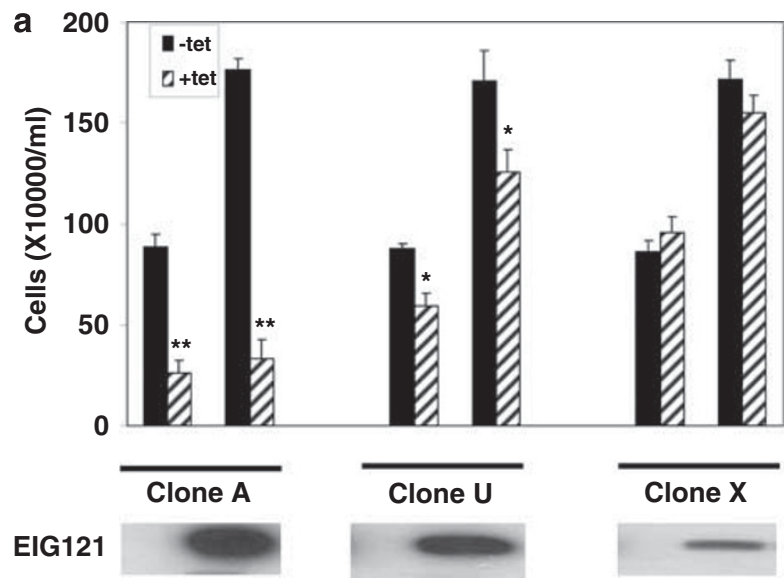

b

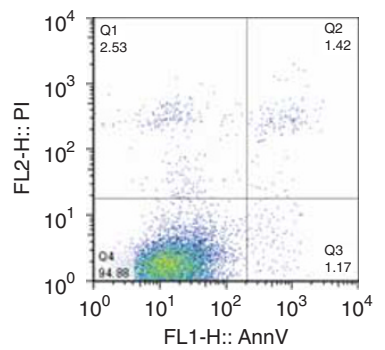

FL1-H:: AnnV

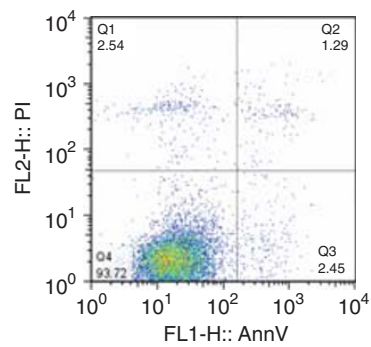

T-Rex-293-EIG121, Clone U
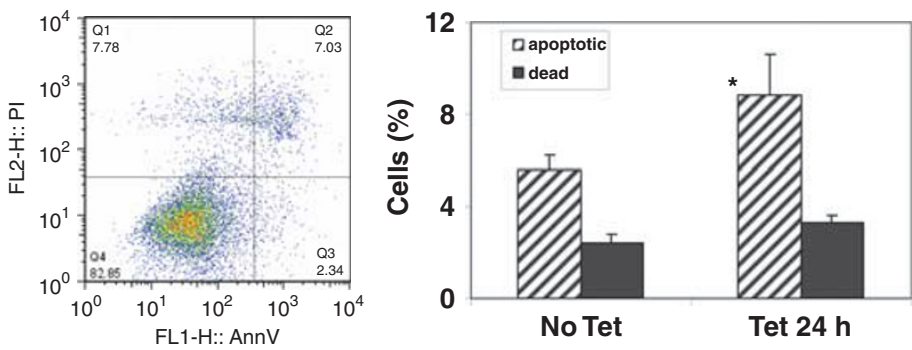

T-Rex-293-LacZ
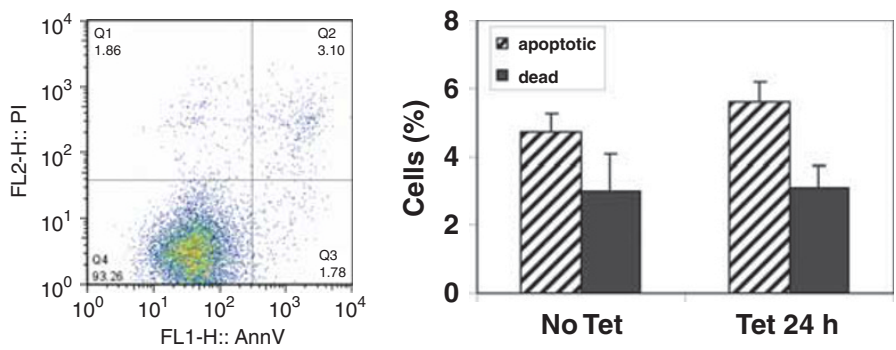

Figure 1 Overexpression of EIG121 leads to growth inhibition and apoptosis. (a) T-Rex-293 cells that express EIG121 at different levels in response to tetracycline treatment were selected. In the upper panel, clones $\mathrm{A}, \mathrm{U}$ and $\mathrm{X}$, which express high, intermediate and modest levels of EIG121, respectively, were plated in quadruplicates in six-well plates and incubated with or without tetracycline for 24 or $48 \mathrm{~h}$. The cells were then trypsinized and counted. Note that the film was overexposed to reveal the EIG121 signal for clone X. (b) T-Rex-293-EIG121 clone U or T-Rex-293-LacZ cells were seeded in triplicates and tetracycline was added for 0 or $24 \mathrm{~h}$. The representative flow cytometry profile represents annexin-V FITC staining in the $x$ axis and PI in the yaxis. The combined percentage of cells in the lower right quadrant (early apoptosis) and upper right quadrant (late apoptosis) represents apoptotic cells, and the upper left quadrant represents dead cells. Plotted in the histograms are the means \pm S.D. of the triplicates; * indicates significance at $P<0.05$ relative to cells without tetracycline induction, while ** indicates significance at $P<0.01$

that EIG121 was highly elevated in endometrioidtype endometrial carcinoma. However, our efforts to overexpress EIG121 constitutively in Ishikawa (an endometrial cancer cell line), 293T cells, and NIH3T3 cells failed, whereas overexpression of LacZ in the same plasmid backbone caused no difficulties. This indicated to us that high levels of EIG121 might be toxic to cells. Therefore, we switched to a tetracycline-inducible system and isolated clones of T-Rex-293-EIG121 cells that express EIG121 at different levels. Overexpression of EIG121 significantly inhibited cell growth, and the extent of inhibition depended on the level of EIG121 expression (Figure 1a). In clone A, which expresses the highest levels of EIG121, cell number was reduced by over $75 \%$ when compared with cells not expressing EIG121.
To determine the mechanism responsible for the observed loss of cells caused by EIG121 expression, we examined the effects of overexpression of EIG121 or LacZ on apoptosis by flow cytometry analysis of annexin V-stained cells. As shown in Figure 1b, even intermediate levels of EIG121 expression significantly increased the percentage of apoptotic cells, whereas overexpression of LacZ did not affect apoptosis.

Necrotic cell death as measured by lactate dehydrogenase $(\mathrm{LDH})$ activity released into the medium was not increased in cells overexpressing EIG121 (data not shown).

EIG121 is a transmembrane protein associated with the plasma membrane and trans-Golgi/late endosomelysosome compartments. To gain an insight into the 


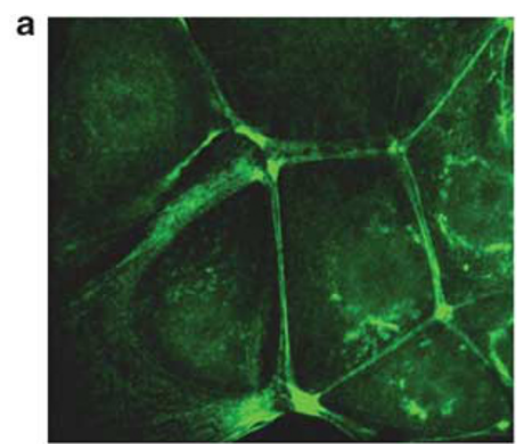

b

\begin{tabular}{|c|c|c|c|c|c|c|}
\hline \multirow{2}{*}{\multicolumn{2}{|c|}{$\begin{array}{c}\text { MCF-7 } \\
\text { Endogenous }\end{array}$}} & \multicolumn{5}{|c|}{ Ishikawa H } \\
\hline & & \multicolumn{3}{|c|}{$\triangle \mathrm{TM}$} & \multicolumn{2}{|c|}{ Wt EIG121 } \\
\hline Mem & Nuc & Cyt & Mem & Nuc & Cyt Mem & Nuc \\
\hline - & & - & & & 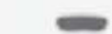 & \\
\hline
\end{tabular}

E-Cadherin

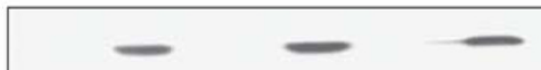

GAPDH

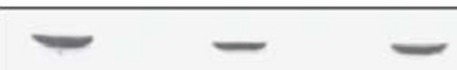

SP1
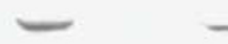

Figure 2 EIG121 is a transmembrane protein associated with the plasma membrane and endomembranes. (a) MCF-7 cells were grown on coverslips and stained with the EIG121 antibody. Note the plasma membrane staining and the perinuclear intracellular localization of EIG121. (b) Untreated MCF-7 cells or Ishikawa cells transfected with plasmids expressing wild-type EIG121 or mutant EIG121 lacking the putative transmembrane domain $(\Delta T M)$ were grown in $10 \mathrm{~cm}$ plates and subcellular fractions were prepared. These fractions were then separated on SDS-PAGE gel and the membrane was probed by various antibodies

mechanisms underlying the growth inhibition and apoptosispromoting properties of EIG121, we first studied its cellular localization. Bioinformatics software predicted that EIG121 had a putative transmembrane domain between amino-acid residues 911 and 931 . Using a polyclonal antibody against the EIG121 C terminus, we determined that in MCF-7 cells, EIG121 was mainly localized to the plasma membrane and cytoplasm in the perinuclear area, with cytoplasmic localization typically polarized to one side of the nucleus (Figure 2a). In some cells, EIG121 also seemed to be associated with cytoskeletal filaments. Subcellular fractionation using lysates from MCF-7 cells, which express relatively high levels of endogenous EIG121, demonstrated that EIG121 was enriched in the membrane extract, but not in the nuclear extract or the cytosol (Figure 2b). Transmembrane domain deletion mutant protein (EIG121 1 TM) was mainly found in the cytosol (Figure 2b) and cell culture medium (not shown), whereas wild-type EIG121 and the mutant with a deletion in the putative mannose-6-phosphate receptor domain (EIG121 $\triangle \mathrm{M} 6 \mathrm{PR}$ ) were still enriched in the membrane preparation (not shown).

Double-labeling experiments revealed that EIG121 partially colocalized with the mannose-6-phosphate receptor (M6PR) (images not shown) and TGN38, two trans-Golgi markers, and Rab 7 (late endosome marker), but not with endoplasmic reticulum (calreticulin) (images not shown) and mitochondria markers. In addition, EIG121 colocalized well with lysosome markers including LAMP1, cathepsin B, and cathepsin D (Figure 3). These results indicate that EIG121 is a transmembrane protein that is associated with plasma membrane/transGolgi/late endosome-lysosome compartments. Localization of EIG121 in T-Rex-293-EIG121 cells that overexpress EIG121 is similar to that of endogenous EIG121 protein in MCF-7 cells (data not shown).

EIG121 induces cytoplasmic vacuolization. T-Rex-293EIG121 cells and MDA-231-t-EIG121 cells (stable cell clones derived from MDA-MB-231 cells to express EIG121 in a tetracycline-inducible manner) overexpressing EIG121 contain large vacuoles. Cytoplasmic vacuoles accumulated $8 \mathrm{~h}$ after EIG121 induction (not shown). By $24 \mathrm{~h}$, the entire cytoplasm was distended with vacuoles (Figure 4a). Although at basal conditions, MDA-MB-231 cells contain some vacuoles, only overexpression of EIG121, but not of LacZ, greatly increased vacuolization (Figure $4 a$ ). It is possible that vacuolization might not be due to EIG121 per se, but instead due to the artifact of overexpression. To rule out this possibility, we transfected cells with wild-type EIG121, EIG121 $\Delta \mathrm{TM}, \quad$ EIG121 $\Delta$ M6PR, and LacZ expression vectors. As all these constructs contain V5 epitag at their C-termini, we applied a V5 antibody to the transfected cells to visualize the expression levels of the exogenous proteins. Although all cells expressed V5-fusion proteins, only expression of wild-type EIG121 and EIG121 $\triangle M 6 P R$, but not of EIG121 $\Delta T M$ and LacZ, induced vacuolization (Figure $4 b$ ).

EIG121 induces the formation of autophagosomes. Autophagy is a highly conserved process in which defective or excess organelles and protein aggregates are sequestered into double-membrane vesicles and delivered to lysosomes for breakdown and recycling. Autophagy has an important role in promoting survival during nutrient deprivation, regulating cellular remodeling during development and differentiation, preventing neurodegeneration, and determining lifespan. ${ }^{3,4}$ As cytoplasmic vacuolation is a hallmark of autophagy, and EIG121 is expressed in lysosomes in which the contents of autophagosomes are degraded, we hypothesized that EIG121 overexpression induced autophagy. By electron microscopy, cells overexpressing EIG121 had abundant double- or multimembranebound structures containing recognizable cellular organelles and electron-dense substances characteristic of autophagosomes and autolysosomes (Figure 5a). In cells induced to express LacZ or not induced by tetracycline, few autophagosomes were detected (data not shown).

Autophagy induction is associated with phosphatidylethanolamine (PE) conjugation to microtubule-associated protein light chain-3 (LC3). Conjugated LC3 moves into autophagosomes and tightly binds to the autophagosome membrane. ${ }^{5}$ Thus, LC3 translocation is a reliable biomarker of autophagy. ${ }^{6,7}$ In cells not expressing EIG121, LC3 was uniformly distributed in the cytoplasm, whereas in cells induced to express EIG121, LC3 expression occurred predominantly in 

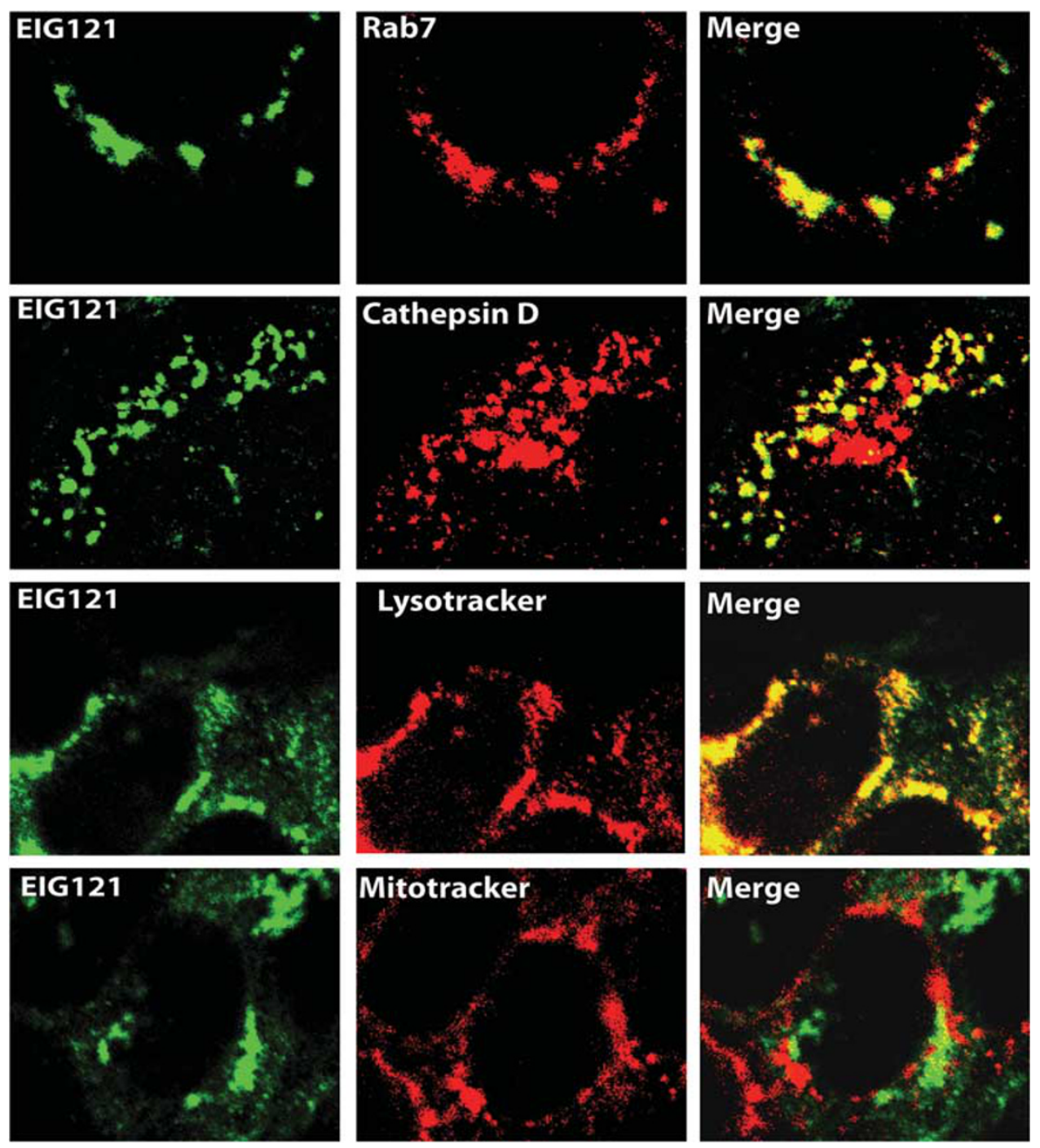

Figure 3 EIG121 localizes in the TGN-late endosome-lysosome compartments. Double immunofluoresence labeling of endogenous EIG121 (green), together with Rab7, cathepsin D, lysotracker and mitotracker (red) in MCF-7 cells

punctuate dot-like structures, consistent with autophagy induction (Figure 5b).

EIG121 enhances lysosomal degradation of long-lived proteins. To quantify the extent of EIG121-induced autophagy, we measured the development of acidic vesicle organelles using acridine orange staining, followed by flow cytometry. As with other acidotropic dyes, red fluorescence generated by acridine orange staining only represents the later-stage autophagosomes and lysosomes; ${ }^{7}$ hence, acridine orange staining underestimates the extent of autophagy. Nevertheless, compared with the no tetracycline control or cells that overexpress LacZ, overexpression of EIG121 greatly increased the percentage of cells that fluoresced. Overexpression of EIG121 for $24 \mathrm{~h}$ increased cells containing acidic organelles by $40 \%$, whereas $48 \mathrm{~h}$ after EIG121 expression, the numbers of cells containing acidic organelles increased 2.5-fold (Figure 6a). Controls overexpressing LacZ did not demonstrate an increase in acridine orange-positive acidic organelles (Figure 6b).

As the contents of autophagosomes are eventually broken down by acidic enzymes inside the lysosomes, we next examined whether EIG121 overexpression affected lysosomal protein degradation. T-RexEIG121 cells were induced to express EIG121, and then cellular proteins were labeled with ${ }^{14} \mathrm{C}$ for $24 \mathrm{~h}$, followed by a $3 \mathrm{~h}$ chase and an overnight chase. During the initial $3 \mathrm{~h}$ chase, short-lived proteins were degraded mainly by the proteosomal mechanism, and medium containing radioactivity was discarded. The longlived proteins were mainly degraded by lysosomal enzymes during the overnight chase. After the secreted proteins and cell debris were removed by trichloroacetic acid (TCA) precipitation from the cell culture medium, the radioactivity remaining in the medium should reflect the protein degradative activity during the chase period. EIG121 expression significantly enhanced the protein degradation activity of the cells (Figure $6 \mathrm{c}$ ). In cells overexpressing EIG121 for 8 or $24 \mathrm{~h}$, 
a

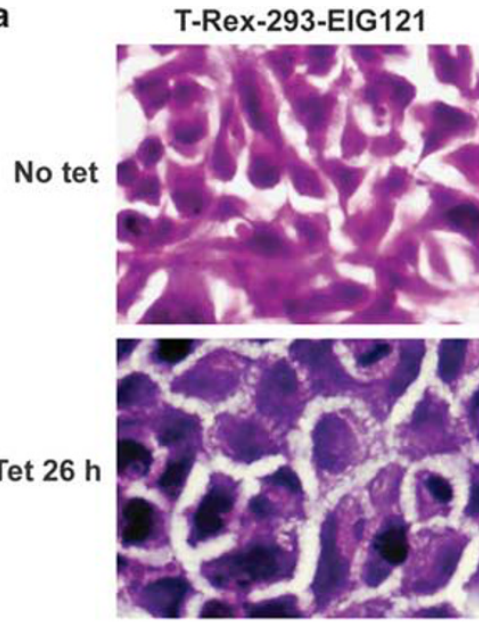

MDA-231-t-EIG121

MDA-231-t-LacZ
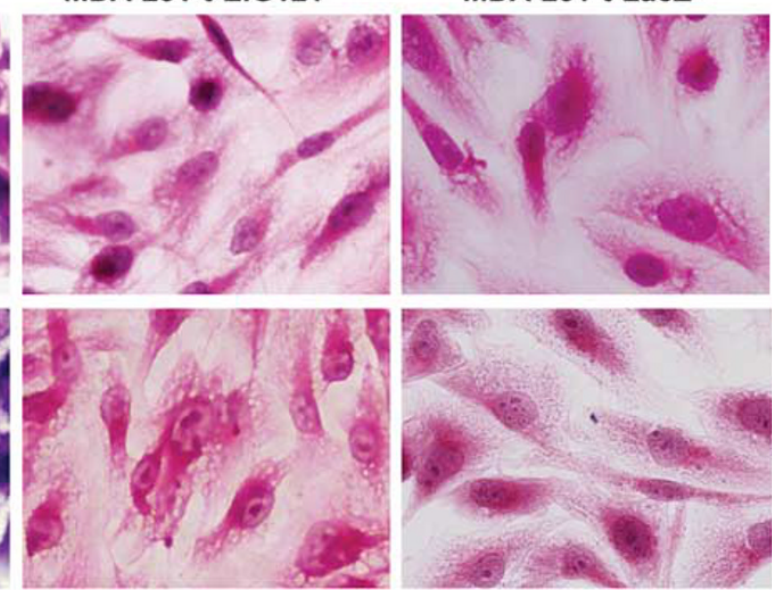

b EIG121
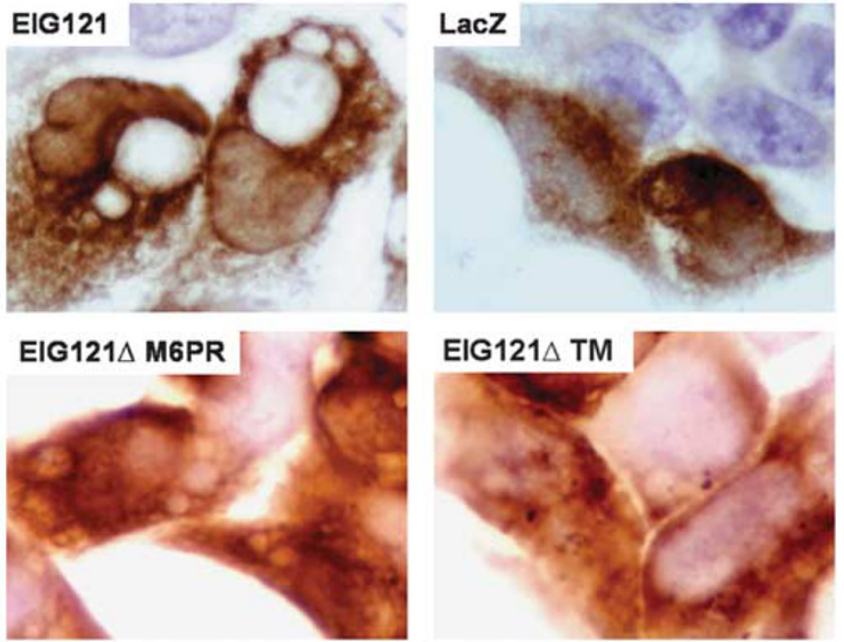

Figure 4 Overexpression of wild-type EIG121, but not of EIG121 $\Delta$ TM and LacZ, induces cytoplasmic vacuolation. (a) T-Rex-293-EIG121 clone A cells, MDA-231-tEIG121, or MDA-231-t-LacZ cells were grown on coverslips, and tetracycline was added for 0 or $26 \mathrm{~h}$. Cells were then fixed and stained with H\&E. (b) Plasmids expressing wild-type EIG121-V5, EIG121 $\Delta$ TM-V5, EIG121 $\Delta$ M6PR-V5, or LacZ-V5 fusion proteins were transfected into Ishikawa H cells, and $48 \mathrm{~h}$ later, the cells were fixed and stained using an antibody against V5

the degradation of long-lived proteins increased significantly by 30 and $37 \%$, respectively.

\section{During starvation-induced autophagy, EIG121 and LC3} translocate into the same vesicles and are degraded by a Iysosomal mechanism. Many proteins that are involved in autophagy cycle between different cell compartments or organelles, and their abundance, may also be controlled. ${ }^{3}$ Thus, we examined whether EIG121 abundance or cellular localization was affected by starvation, a strong inducer of autophagy. During autophagy, the autophagosome marker LC3 is conjugated with PE and translocates into the membranes of autophagosomes and to a lesser extent of autolysosomes. After autophagosomes are fused with lysosomes, LC3 on the intra-autophagosomal membrane is rapidly degraded by lysosomal proteases, and therefore the amount of LC3-I and LC3-II at certain time points after starvation can be either increased or reduced, depending on different cell contexts and the length of starvation. ${ }^{8,9}$ Because of the dynamic changes of LC3 during an autophagy, LC3 has been used as a surrogate marker for autophagy. We therefore also examined the changes in endogenous LC3 after starvation in these cells. As shown in Figure $7 \mathrm{a}$, within $30 \mathrm{~min}$ of starvation, both EIG121 and LC3 levels were reduced by $70 \%$. After $2 \mathrm{~h}$ of starvation, both LC3-I (the nonconjugated form) and LC3-II (PE-conjugated form) almost completely disappeared, whereas EIG121 reduction slowed after the initial $30 \mathrm{~min}$ of starvation and was never as complete as LC3 loss. As the decrease in EIG121 and LC3 proteins occurred rapidly after starvation, their decrease is likely to be due to protein degradation. To differentiate the two major protein degradation mechanisms, we then starved MCF-7 cells and treated them with bafilomycin $\mathrm{A} 1$ (BafA1), an agent that elevates lysosomal $\mathrm{pH}$ and inhibits lysosomal fusion, and the proteosomal inhibitor MG132. BafA1 completely blocked the starvationinduced degradation of EIG121 and LC3, whereas MG132 had little effect, suggesting that EIG121 and LC3 were both degraded by a lysosomal mechanism during starvation (Figure 7b). 
a

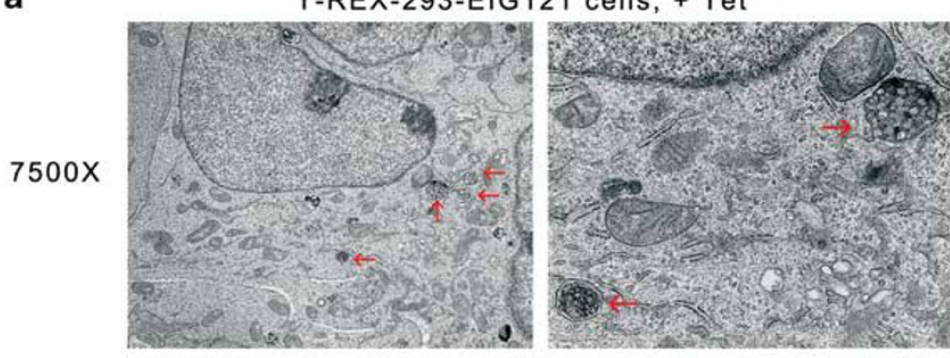

T-REX-293-LacZ cells, + Tet

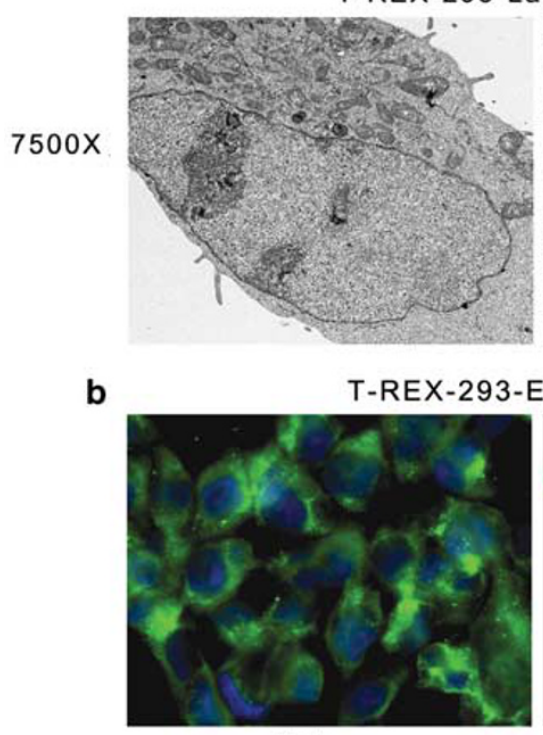

-Tet

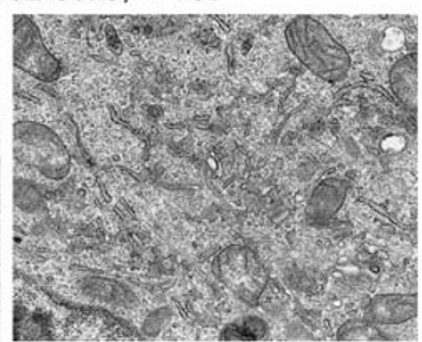

$25000 x$
$25000 x$

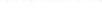

Figure 5 Overexpression of EIG121 induces the formation of autophagsosomes and translocation of the autophagosome marker LC3 into dot-like vesicles. (a) T-Rex-293EIG121 or T-Rex-293-LacZ cells were incubated with or without tetracycline for $24 \mathrm{~h}$, fixed, and then examined by electron microscopy. Note that in the upper panels, autophagsomes were easily detected (arrows), whereas in cells not expressing EIG121 (lower panels), few autophagosomes were formed. (b) T-Rex-293-EIG121 clone A cells were grown on coverslips, and tetracycline was added in half of the wells for $24 \mathrm{~h}$. Cells were then fixed and stained using an antibody against LC3

In nonstarved MCF-7 cells, EIG121 mainly localized to the plasma membrane and to the cytoplasm in the perinuclear region, with polarization to one side of the nucleus (Figure $7 \mathrm{c}$ ). In contrast, 30 min after cell starvation, bright EIG121-positive vesicular structures began to scatter in the cell cytoplasm. After $1 \mathrm{~h}$ of starvation, larger EIG121-positive vesicles became evident, whereas the intensity of the perinuclear EIG121 staining was markedly reduced. In nonstarved MCF-7 cells, LC3 was uniformly distributed in the cytoplasm, with occasional large, punctate staining in the perinuclear region (Figure 7c). After starvation, cytoplasmic LC3 decreased dramatically, whereas the large punctate staining was not affected.

The results of Figure $7 a$ and $b$ suggested that EIG121 and LC3 encounter the same fate after starvation, namely, lysosome-mediated protein degradation. We next determined whether these two proteins move into the same vesicles after starvation. For this purpose, a different LC3 antibody generated in a mouse was obtained (MBL International Corporation, Woburn, MA, USA). As both EIG121 and LC3 were degraded after starvation for $30 \mathrm{~min}$, we studied the possible colocalization of these two before $30 \mathrm{~min}$. As shown in Figure 7d, in nonstarved MCF-7 cells, EIG121 densely localized in the perinuclear region, whereas LC3 was uniformly distributed in the cytoplasma. After starvation for $20 \mathrm{~min}$, scattered EIG121-positive vesicles strongly colocalized with the large LC3-decorated vesicles.

\section{Knockdown of EIG121 compromises starvation-induced} autophagy and sensitizes cells to cell death induced by nutrient deprivation and exposure to cytotoxic agents. To determine whether EIG121 is necessary for autophagy, we examined the effect of EIG121 knockdown on starvation-induced LC3 degradation. EIG121 knockdown resulted in about $70 \%$ reduction in EIG121 protein expression, and this was associated with compromised starvation-induced LC3 degradation as determined by immunofluorescence (IF) (Figure 8a) and western blotting (Figure 8b).

Autophagy promotes cell survival under nutrient deprivation and other stressful conditions. ${ }^{4,10}$ We hypothesized that EIG121 contributes to such autophagic protective mechanisms. Knockdown of EIG121 by itself did not affect cell survival (Figure 9a, first row) as evidenced by similar staining patterns between control and EIG121 siRNA-transfected cells by TUNEL assay. After serum starvation (Figure 9a, middle row) or paclitaxel treatment (Figure 9a, bottom row), EIG121 

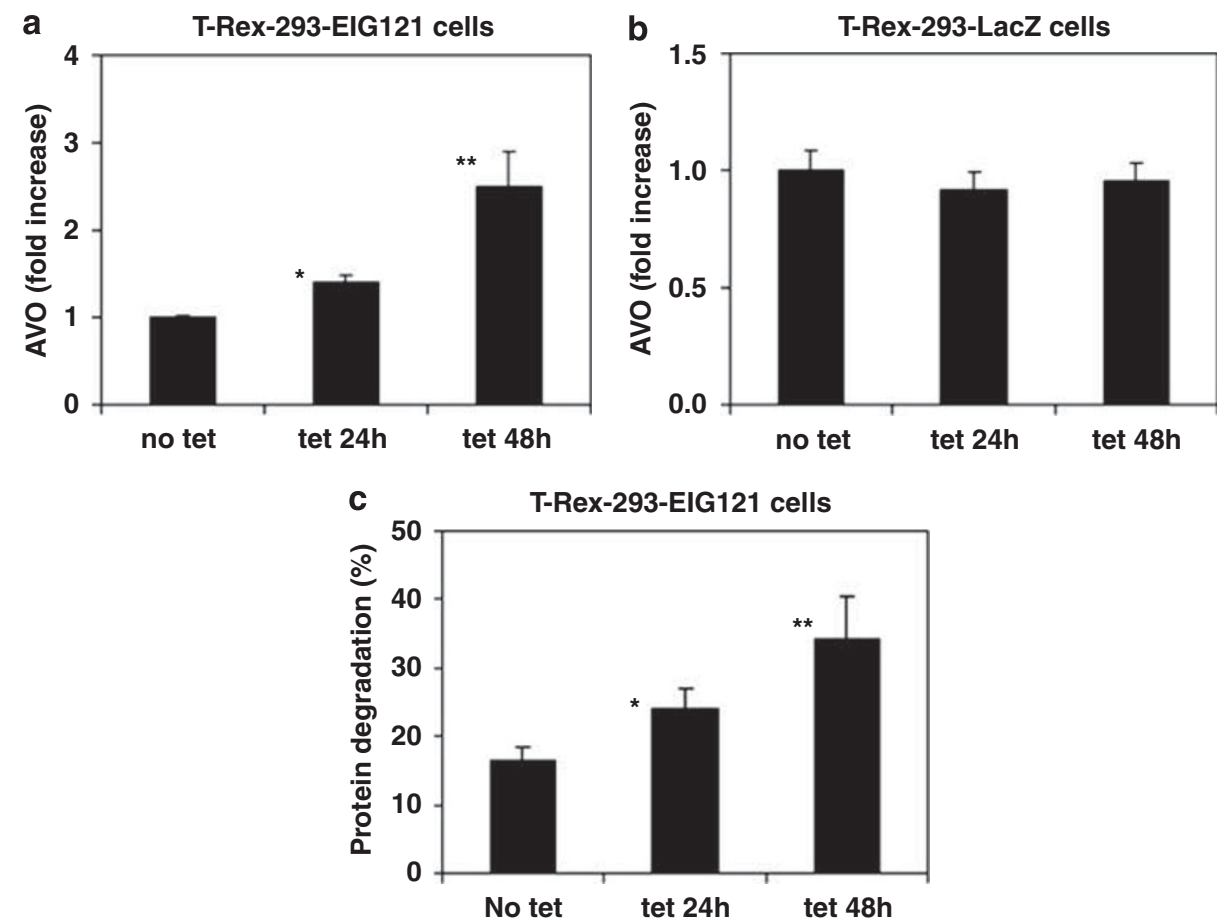

Figure 6 Overexpression of EIG121 increases acidic vesicles and the degradation of long-lived proteins. T-Rex-293-EIG121 clone A cells (a) or T-Rex-293-LacZ cells (b) were grown in six-well plates and incubated without or with tetracycline for 24 or $48 \mathrm{~h}$. Cells were then incubated in medium containing acridine orange and collected by trypsinization for flow cytometry analysis. Plotted are fold increase of cells containing acidic vesicular organelles. (c) T-Rex-293-EIG121 clone A cells were grown in 12-well plates and incubated in the presence or absence of tracycline for either 8 or $24 \mathrm{~h}$. Cells were then labeled in medium containing ${ }^{14} \mathrm{C}$-valine and chased first for $3 \mathrm{~h}$ to deplete short-lived proteins and then for another $16 \mathrm{~h}$. The degradation of long-lived proteins was represented by the radioactivity released into the medium during the last $16 \mathrm{~h}$ (the ratio of TCA-soluble radioactivity to the total cellular radioactivity). Each group contained five replicates, and data shown (mean \pm S.E.M.) are representative of three independent experiments

knockdown greatly increased the percentage of cells undergoing apoptosis. Cleaved caspase 3 was undetectable in MCF-7 cells, but cleaved caspase 7 was markedly increased in EIG121 siRNA-transfected cells. EIG121 knockdown increased the basal levels of cleaved caspase 7 when compared with the nontransfected control and the nontargeting siRNA control (Figure 9b). Serum deprivation (for $48 \mathrm{~h}$, lanes 4-6), nutrient starvation (lanes 7-9), and doxorubicin treatments (lanes 10-15) increased cleaved caspase 7, but EIG121 knockdown exaggerated this increase. These results suggest that EIG121 depletion compromised cell survival under various cellular stresses.

\section{Discussion}

In this study, we have demonstrated that the novel estrogeninduced gene EIG121 has a role in autophagy and that this function may promote cell survival under nutrient deprivation and other cellular stresses. Subcellular fractionation (Figure 2) and confocal microscopy (Figure 3) showed that EIG121 is a transmembrane protein associated with the compartments of the plasma membrane, trans-Golgi network (TGN), late endosomes, and lysososomes. Therefore, we highly suspected that EIG121 may have a role in intracellular membrane trafficking processes involving these organelles. One such trafficking process is autophagy. During autophagy, excessive, old and unneeded macromolecules, including long-lived proteins and organelles, are first enwrapped by a doublelayered membrane to form autophagosomes. Thereafter, autophagosomes receive lysosomal enzymes by fusing with transporting vesicles originated from the TGN or lysosomes. Finally, the engulfed materials are degraded by lysosomal enzymes, and amino acids and other small molecules are recycled. $^{3,11}$ Numerous studies have shown that TGN proteins have important roles in autophagy. Beclin-1, Ptdlns 3-kinase, and ATG9, three proteins required for autophagy, localize to the TGN in nutrient-sufficient conditions, but are redistributed to autophagosomes and lysosomes during starvation-induced autophagy. ${ }^{12-14}$ Rab7, a late endosomal protein, is necessary for the maturation of late autophagosomal vacuoles. ${ }^{15}$ As the final stage of autophagy involves the fusion of autophagosomes with lysosomes and the degradation of engulfed materials by lysosomal enzymes, there is no doubt that lysosomal proteins are important for autophagy. This is evidenced by the blockade of autophagy using lysosomal inhibitors $^{16,17}$ and by the defective autophagic responses in lysosomal storage diseases or knockout animal models of lysosomal proteins. ${ }^{18,19}$

During starvation, LC3-I (cytoplasmic) is converted into LC3-II (membrane bound), and after the fusion of autophagosomes with lysosomes, intra-autophagosomal LC3-II is rapidly degraded by lysosomal proteases. Consistent with this idea, we observed that on starvation, EIG121 was redistributed into LC3-positive vesicles and then both LC3 
a

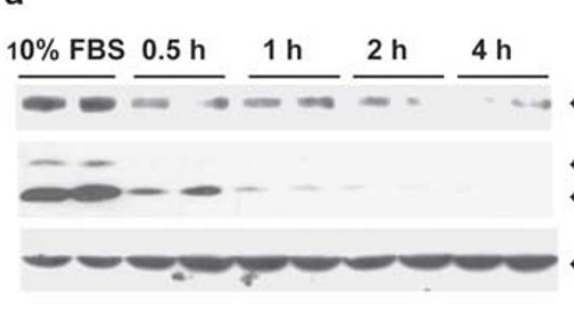

C

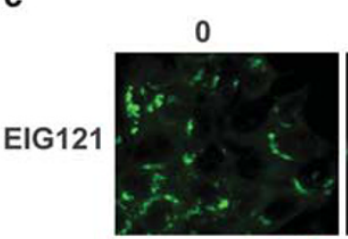

LC3

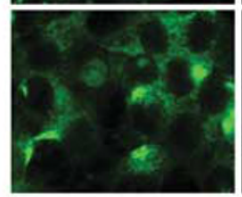

d
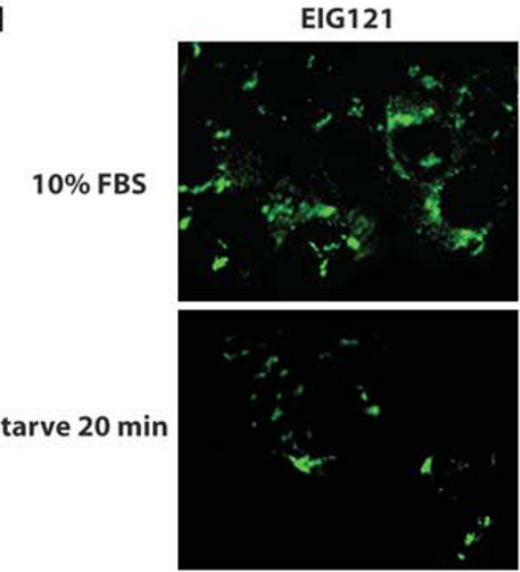

$0.5 \mathrm{~h}$

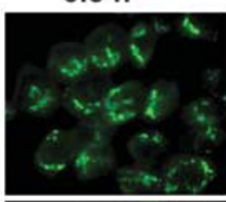

Starve
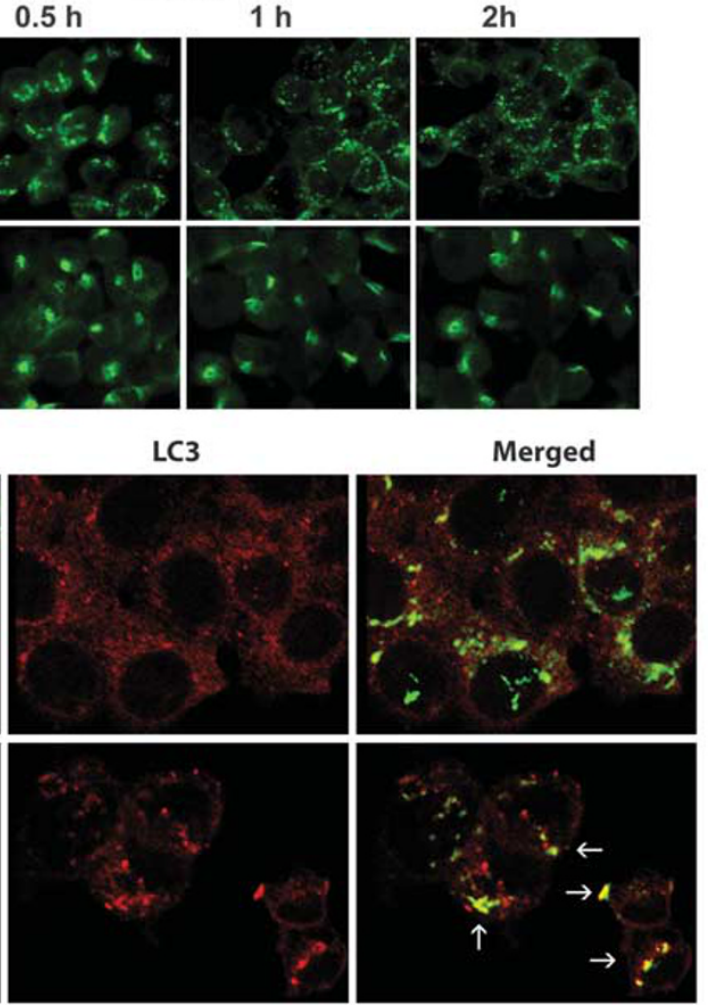

Figure 7 After starvation, EIG121 and LC3 colocalize and both are degraded by a lysosomal mechanism. (a) MCF-7 cells were starved in HBSS for $0,0.5,1,2$, and $4 \mathrm{~h}$. Note the rapid degradation of EIG121 and both LC3-I and LC3-II on starvation. This experiment was conducted twice and each time with all the treatment groups in duplicate. (b) The starvation-induced degradation of EIG121 and LC3 is blocked by lysosomal inhibitor BafA1. MCF-7 cells were pretreated with either BafA1 (100 nM) or MG132 (10 $\mu \mathrm{M}$ ) for $30 \mathrm{~min}$, before being starved in HBSS for $2 \mathrm{~h}$ in the continuous presence of BafA1 or MG132. Either 50 or $150 \mu \mathrm{g}$ of cell lysates was resolved by SDS-PAGE gel and probed by EIG121 or LC3 antibodies, respectively. (c) Immunofluorescence staining of EIG121 and LC3 at different times after starvation. A rabbit polyclonal antibody against LC3 was used. Note the scattered vesicular staining of EIG121 after starvation. (d) EIG121 and LC3 double labeling of MCF-7 cells cultured in 10\% FBS or starved in HBSS for $20 \mathrm{~min}$. In this experiment, a mouse monoclonal antibody against LC3 was used. The arrows indicate colocalized LC3- and EIG121-positive vesicles

and EIG121 were degraded (Figure 7). The amount of cellular LC3-I and LC3-II at a certain time point in a given cell is highly dynamic and cell context dependent. For example, LC3-II is increased in HEK293 cells after $2 \mathrm{~h}$ of incubation in KRB starvation buffer, whereas the same treatment leads to a reduction in both LC3-I and LC3-II in HeLa cells. ${ }^{8}$ Amino-acid starvation of colorectal cancer cell lines leads to increased LC3 in SW620 and WiDr cells, but decreased LC3 in SW480 and LoVo cells. ${ }^{9}$ In our study, we found that, in MCF-7 cells, LC3-II is the dominant form of LC3 and that, on starvation, both LC3 and EIG121 were rapidly degraded (Figures $7 a$ and b). However, in MDA-MB-231 cells, LC3-I is the dominant form and that during early time points of starvation (5 to $30 \mathrm{~min}$ ) LC3-II increases, whereas prolonged starvation ( $30 \mathrm{~min}$ to $2 \mathrm{~h}$ ) leads to profound degradation of LC3 (data not shown). We believe that the degradation of LC3 and EIG121 occurred in lysosomes, as BafA1, an agent that elevates lysosomal pH and inhibits fusion with lysosomes, ${ }^{16}$ completely abolished starvation-induced degradation of EIG121 and LC3 (Figure 7b). As LC3 is recognized as a biomarker of autophagy, the results presented here indicate that EIG121 has a role in autophagy induced by starvation and cytotoxic drug treatment. However, the precise function of EIG121 in autophagy and the mechanism underlying this function are still unclear and should be the focus of future studies.

We first described EIG121 as an estrogen-induced gene that was overexpressed in estrogen-dependent endometrial endometrioid adenocarcinoma, but not estrogen-independent 
a

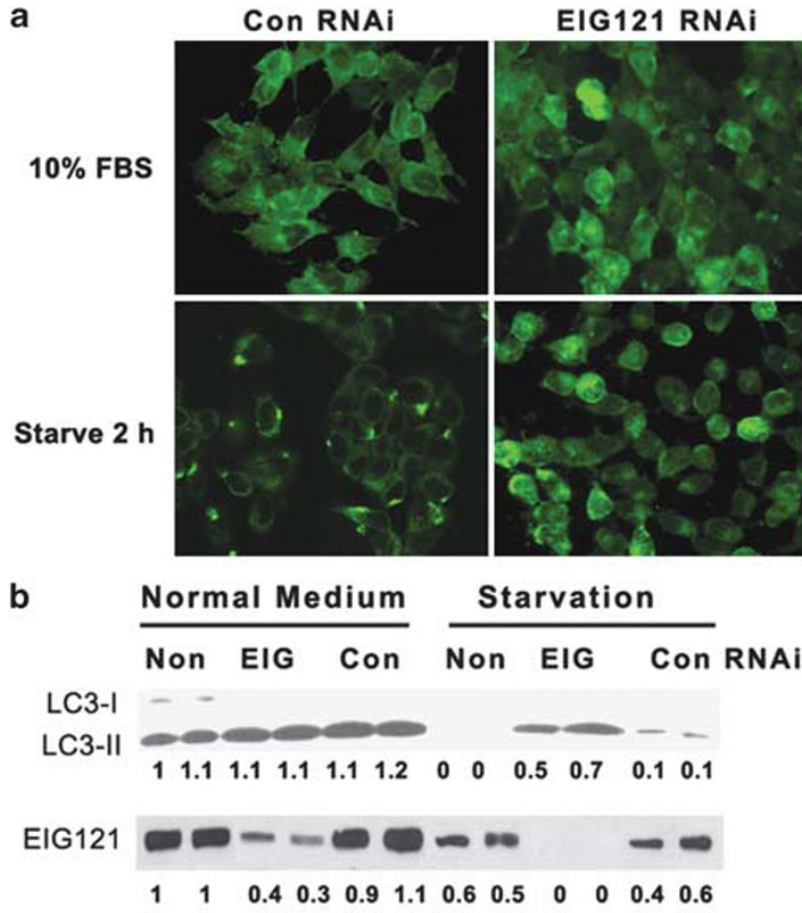

$\beta$-actin

Figure 8 EIG121 knockdown compromises starvation-induced autophagy. (a) EIG121 siRNA blocked starvation-induced LC3 degradation. MCF-7 cells were transfected with control nontargeting siRNA or EIG121 siRNA for $72 \mathrm{~h}$ and then starved in HBSS for $2 \mathrm{~h}$. Cells were then fixed and stained for LC3. (b) MCF-7 cells were transfected with siRNAs in duplicate and starved as in $\mathrm{A}$, but cell lysates were harvested and probed with an LC3 or EIG121 antibody using western blotting. A representative of one of the three independent experiments is shown. The densities of lanes relative to the first lane of nonstarved cells are shown below the blots. Abbreviations: non, nontransfected cells (no siRNA); EIG, EIG121 siRNA; con, control nontargeting siRNA

nonendometrioid endometrial carcinoma. ${ }^{1}$ The role of autophagy in cancer remains controversial. On one hand, deficiency in autophagic genes such as beclin-1 has been detected in various cancers, and mice with beclin- 1 haploinsufficiency are more prone to tumorigenesis. ${ }^{20}$ Tumor suppressors such as p53 can positively regulate autophagy, whereas oncogenic molecules such as mTOR are negative regulators of autophagy. ${ }^{21-23}$ These observations suggest that autophagy suppresses tumorigenesis. On the other hand, autophagy is well known to promote the survival of normal and tumor cells under stressful conditions such as nutrient deprivation and cytotoxic drug treatment and may thus facilitate tumor development and resistance to therapy. ${ }^{24,25}$ These contradictory observations suggest that the role of autophagy in tumorigenesis may be dependent on levels of proteins that regulate autophagy, the cell type, and the microenvironment. Some recent studies have demonstrated that normal cell growth requires a balance in the autophagic pathway and that both insufficient and excessive levels of autophagy may inhibit survival and trigger cell death. ${ }^{4,26}$ In this study, we observed that overexpression of EIG121 led to growth inhibition and apoptosis (Figure 1a). EIG121 knockdown alone did not affect cell survival, but when combined with nutrient deprivation or cytotoxic drug treatment, led to massive cell death (Figure 9). These results suggest that tumor cells may not depend on EIG121 when sufficient nutrients are present, but EIG121-induced autophagy may promote temporary cell survival under stressful conditions. Autophagic activity is most prominent in the center of early mammary gland tumors, in which there is limited supply of nutrients and oxygen, because of the lack of tumor-induced angiogenesis. ${ }^{27}$ Therefore, it is possible that the high levels of EIG121 that we previously observed in endometrial hyperplasia and grade 1 endometrial carcinoma contribute to the survival of these early abnormal proliferations, when the exogenous nutrient supply is extremely limited, by inducing autophagy. In more advanced endometrioid carcinomas and nonendometrioid carcinomas, as massive angiogenesis and elevated growth factor signaling can support tumor growth, EIG121 is not required for tumor survival. In fact, the continuous presence of high-level EIG121 in these tumors might lead to growth arrest and cell death, as prolonged and excessive autophagy contributes to the execution of cell death. ${ }^{28,29}$ We speculate that because of the metabolic catastrophe induced by excessive autophagy, EIG121 is eliminated from advanced carcinomas. For the same reason, we could not establish stable cells that constitutively expressed EIG121 at high levels.

The reason why MCF-7 cells in vitro and low-grade endometroid endometrial carcinomas can tolerate relatively high levels of EIG121 is currently unclear. It is possible that MCF-7 cells and low-grade endometrial tumors bear additional genetic or epigenetic alterations that can antagonize the growth inhibitory and pro-death effects caused by prolonged and excessive EIG121 expression. In addition, the role of EIG121 in cancer is likely to be tumor developmental stage and cell context dependent. For example, TGF- $\beta$ is a tumor suppressor in early phases of tumorigenesis, but promotes progression in later stages. ${ }^{30}$ Even the classical tumor suppressor PTEN can have tumor-promoting properties in the setting of gain-of-function p53 mutations. ${ }^{31}$ Therefore, it is not surprising that EIG121 may have very different roles in early endometrioid-type endometrial carcinomas compared with advanced tumors and nonendometrioid-type tumors.

The fact that EIG121 is positively regulated by estrogen raises the issue of the role of estrogen in autophagy regulation and the function of autophagy in estrogen-responsive tissues. Steroid hormones, such as ecdysone, vitamin D, and glucocorticoids, have been shown to induce autophagy strongly. ${ }^{32-34}$ In fact, ecdysone-induced autophagy is required for the degradation of salivary glands, body fat, and the midgut to allow for tissue remodeling and morphogenesis for the transformation of worm-like larvae into adult flies. ${ }^{35}$ Selective estrogen receptor modulators, including tamoxifen and resveratrol, have also been shown to induce autophagy, ${ }^{36,37}$ and the estrogen receptor coactivator PELP1 translocates into autophagosomes after resveratrol treatment. ${ }^{38}$ It is possible that estrogens, through either PELP1- or EIG121-mediated pathways, modulate the self-digestive activities of uterine endometrium and mammary gland tissues to accommodate the remodeling of endometrial tissues during the menstrual cycle and the lactation and involution of mammary glands. 


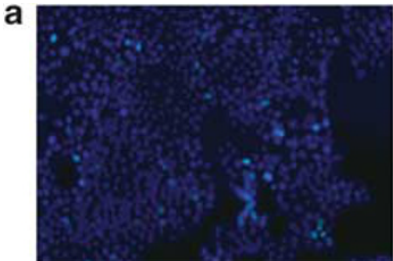

No siRNA; $10 \%$ FBS

Ap. Index $=8.2 \%$

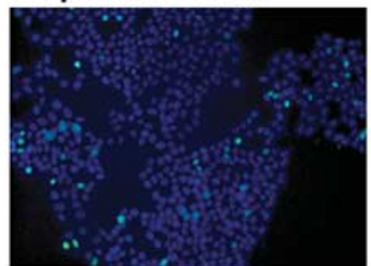

No siRNA; O FBS

Ap. Index $=11.4 \%$

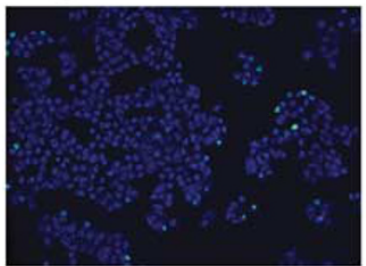

No siRNA; Taxol

Ap. Index $=11.4 \%$

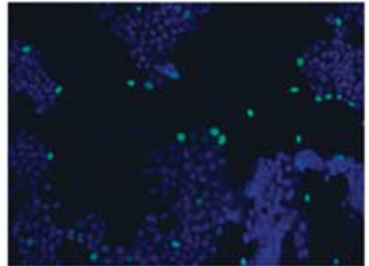

EIG121 siRNA; 10\% FBS

Ap. Index $=9.6 \%$

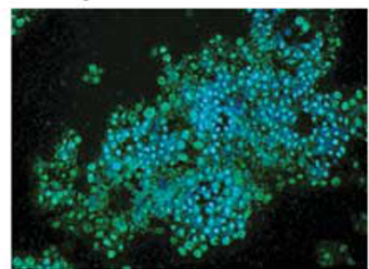

EIG121 siRNA; 0 FBS

Ap. Index $=98.8 \%$ **

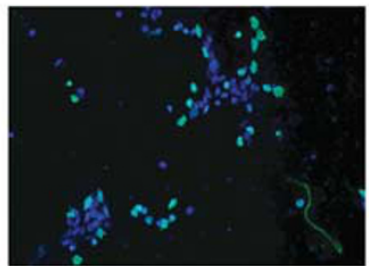

EIG121 siRNA; Taxol

Ap. Index $=44.9 \%$ **

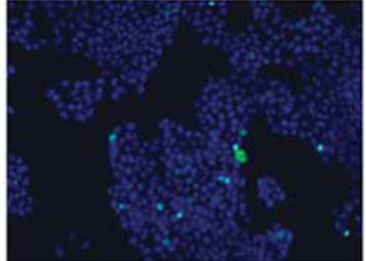

Con siRNA; $10 \%$ FBS

Ap. Index $=7.5 \%$

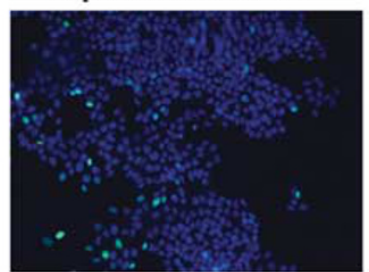

Con siRNA; O FBS

Ap. Index $=13.3 \%$

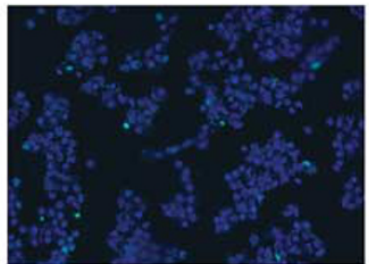

Con siRNA; Taxol

Ap. Index $=9.3 \%$

b

\begin{tabular}{|c|c|c|c|c|c|c|c|c|c|c|c|c|c|c|}
\hline \multicolumn{3}{|c|}{ No treatment } & \multicolumn{3}{|c|}{ No FBS $48 \mathrm{~h}$} & \multicolumn{3}{|c|}{ HBSS 2h } & \multicolumn{3}{|c|}{$\begin{array}{l}\text { DOX } 1 \mu \mathrm{M} \\
6 \mathrm{~h} \\
\end{array}$} & \multicolumn{3}{|c|}{$\begin{array}{c}\text { DOX } 0.1 \mu \mathrm{M} \\
24 \mathrm{~h} \\
\end{array}$} \\
\hline & & 6 & $\mathbf{N}$ & 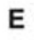 & & 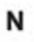 & 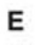 & C & $\mathrm{N}$ & E & C & N & 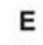 & \\
\hline & 2 & 3 & 4 & 5 & 6 & 7 & 8 & 9 & 10 & 11 & 12 & 13 & 14 & \\
\hline
\end{tabular}

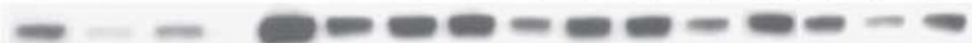

EIG121

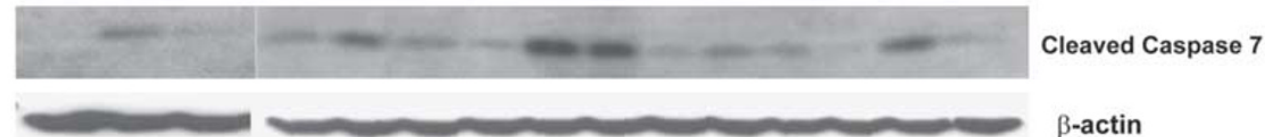

Figure 9 EIG121 knockdown decreases cell viability under conditions of serum deprivation or cytotoxic drug treatments. (a) MCF-7 cells were transfected with control nontargeting siRNA or EIG121 siRNA for $48 \mathrm{~h}$ and incubated in medium with $10 \% \mathrm{FBS}$ or serum-free medium for $48 \mathrm{~h}$ or treated with $20 \mathrm{nM}$ of paclitaxel (taxol) for $16 \mathrm{~h}$. Cells were then fixed for TUNEL staining. For each experiment, apoptotic cells (stained green) were quantified among $\sim 2000$ total cells (stained blue), and the apoptotic index was computed by dividing the number of apoptotic cells by the number of total cells. ** indicates significance at $P<0.01$ level, relative to control nontargeting siRNA groups. (b) MCF-7 cells were transfected with control nontargeting siRNA or EIG121 siRNA for $48 \mathrm{~h}$ and then treated as indicated. Cells were ruptured, and EIG121, cleaved caspase 7 , and $\beta$-actin were probed using specific antibodies. N, nontransfected cells (no siRNA); E, EIG121 siRNA; C, control nontargeting siRNA

\section{Materials and Methods}

Cloning of wild-type and mutant EIG121 expression vectors and establishment of EIG121 overexpressing cell clones. The fulllength human EIG121 open reading frame was obtained from normal human endometrial tissue by RT-PCR, using primers designed according to the sequence of NM_020775. The PCR product was then cloned into either pcDNA3.1D/N5/His or pcDNA4/TO vector (Invitrogen, Carlsbad, CA, USA). To delete the putative transmembrane domain and M6PR domain, a site-directed mutagenesis kit from Stratagene (La Jolla, CA, USA) was used with the following primers: DelTM-F 5'-GATTTCTGGCTGAAATGGAAAAAGAATCAAAAACTAGAGTAC-3', DelTM-R 5'-GTACTCTAGTTTTTGATTCTTTTTCCATTTCAGCCAGAAATC-3', Del 26662704F 5'-GATGGGACCTGTGATGGCCCGCTCTGCTCAGTGGC-3' and Del 2666-2704R 5'-GCCACTGAGCAGAGCGGGCCATCACAGGTCCCATC-3'. To generate stable cells that overexpress EIG121 in a tetracycline-inducible manner, T-Rex-293 cells containing the tetracycline repressor pcDNA6/TR were obtained from Invitrogen. MDA-MB-231 breast cancer cells containing pcDNA6/TR were a generous gift from Dr. Peter Storz at the Mayo Clinic. The plasmids pcDNA4/TO/ EIG121 or pcDNA4/TO/LacZ were then transfected into these cell lines by Fugene- 6
(Roche Applied Science, Indianapolis, IN, USA) and individual clones were selected in the presence of blastidin and zerocin.

Starvation, serum withdrawal, and paclitaxel/doxorubicin treatments. For amino-acid starvation, cells were first extensively washed with Hank's balanced salt solution (HBSS) and further incubated in HBSS for $30 \mathrm{~min}$ to $4 \mathrm{~h}$ as indicated in figure legends. For serum deprivation, MCF-7 cells were washed twice with PBS and then incubated in serum-free DMEM for 24 to $48 \mathrm{~h}$. For taxol treatment, MCF-7 cells transfected with control nontargeting siRNA or EIG121 siRNA were incubated overnight $(16 \mathrm{~h})$ in standard growth medium containing $20 \mathrm{nM}$ paclitaxel. For doxorubicin treatments, MCF-7 cells transfected with control nontargeting siRNA or EIG121 siRNA were incubated in growth medium containing $1 \mu \mathrm{M}$ doxorubicin for $6 \mathrm{~h}$ or containing $0.1 \mu \mathrm{M}$ doxorubicin for $24 \mathrm{~h}$.

Determination of apoptotic and necrotic cell death. The following three different methods were used to detect apoptosis: (1) labeling the free $3^{\prime}-\mathrm{OH}$ termini with terminal transferase (TUNEL assay); (2) quantification of the 
externalization of phosphatidylserine by annexin- $V$ staining, followed by flow cytometry analysis; and (3) measuring cleaved caspases by immunoblotting. Both the in situ cell death detection (fluorescein) kit and the annexin-V staining kit were from Roche, and the manufacturer's instructions were followed. Antibodies against cleaved caspases were from Cell Signaling Technology (Danvers, MA, USA). LDH activity in culture medium was measured as an indicator of damage to the cell membrane during necrotic cell death. For this purpose, the Cytotoxicity Detection Kit (LDH) from Roche Applied Science was used.

Subcellular fractionation. MCF-7 breast cancer cells or Ishikawa $\mathrm{H}$ endometrial cancer cells transfected with pcDNA3.1D/EIG121/N5/His or LacZ, EIG121 mutants EIG121 $\triangle T M$ (deletion of the transmembrane domain) or EIG121 $\triangle M 6 P R$ (deletion within the putative M6PR domain) were grown on $10 \mathrm{~cm}$ plates and after two washes with PBS were incubated in $500 \mu \mathrm{l}$ hypotonic CLB buffer (10 mM HEPES, $10 \mathrm{mM} \mathrm{NaCl}, 1 \mathrm{mM} \mathrm{KH}_{2} \mathrm{PO}_{4}, 5 \mathrm{mM} \mathrm{NaHCO}_{3}, 1 \mathrm{mM}$ $\mathrm{CaCl}_{2}, 0.5 \mathrm{mM} \mathrm{MgCl}_{2}, 5 \mathrm{mM}$ EDTA, plus a cocktail of protease inhibitors from Roche Applied Science) on ice for $10 \mathrm{~min}$. Swollen cells were then harvested using a cell scraper, and the mixtures were homogenized with a Dunce homogenizer for 30 strokes. The resulting lysates were then centrifuged at $6300 \mathrm{~g}$ for $5 \mathrm{~min}$ after adding $50 \mu \mathrm{l} 2.5 \mathrm{M}$ sucrose. The resulting pellets were resuspended in TSE buffer $(10 \mathrm{mM}$ Tris pH 7.5, $300 \mathrm{mM}$ sucrose, $1 \mathrm{mM}$ EDTA, $0.1 \%$ NP-40) as nuclear extracts and cell debris. The supernatants were further centrifuged at 13000 r.p.m. for $2 \mathrm{~h}$. The resulting pellets were resuspended in RIPA buffer $(50 \mathrm{mM}$ Tris- $\mathrm{HCl}, \mathrm{pH} 7.4,150 \mathrm{mM}$ $\mathrm{NaCl}$, EDTA $1 \mathrm{mM}, 1 \% \mathrm{NP}-40,0.25 \%$ Na-deoxycholate) as membrane extracts (and organelles), and the supernatants were considered as the cytosolic fraction. To reduce the volume of cytosolic fractions, they were concentrated using Centricon Centrifugal Filter Units (Millipore, Billerica, MA, USA). To ensure equal loading among lanes, after transferring the proteins onto the membrane from the gel, the membrane was stained with Ponceau S before probing with primary antibodies.

Immunofluorescence staining. The EIG121 antibody was generated by injecting the C-terminal peptide TSKRTPDGFDSVPLKTC into rabbits and the antiserum was affinity purified. Other antibodies used were obtained from the following sources: mouse monoclonal antibodies against EEA1 and calreticulin from GeneTex (San Antonio, TX, USA), goat polyclonal antibodies against Rab 7 and TGN38 from Santa Cruz Biotechnology (Santa Cruz, CA, USA), mouse monoclonal antibody against LAMP1 from Abcam (Cambridge, MA, USA), and goat polyclonal antibodies against cathepsins $B$ and $D$ from R\&D Systems (Minneapolis, MN USA). Dye-labeled secondary antibodies were from Molecular Probes (La Jolla, CA, USA). For IF labeling, cells were grown on cover glasses and fixed in $4 \%$ paraformaldehyde. EIG121 antibody (1:100) alone or in combination with other antibodies in $10 \%$ normal fetal bovine serum was added to the cells for overnight incubation at $4^{\circ} \mathrm{C}$ After extensive washing in PBS, cover glasses were incubated with proper combinations of dye-conjugated secondary antibodies $(1: 400)$ in $10 \%$ normal goat serum for $1 \mathrm{~h}$ at room temperature. The cover glasses were then washed extensively with PBS and mounted using a mounting medium containing anti-fade agent and DAPI (Invitrogen). After curing, the slides were examined using fluorescent or confocal microscopy.

Examination of autophagosomes by electron microscopy. T-RexEIG121 or T-RexLacZ cells were grown on six-well plates and incubated in the absence or presence of $1 \mu \mathrm{g} / \mathrm{ml}$ tetracycline for 24 or $48 \mathrm{~h}$. Cells were then fixed with a solution containing $3 \%$ glutaraldehyde plus $2 \%$ paraformaldehyde in $0.1 \mathrm{M}$ cacodylate buffer $(\mathrm{pH} 7.3)$ for $1 \mathrm{~h}$. The samples were then postfixed in $1 \% \mathrm{OsO}_{4}$ in the same buffer for $1 \mathrm{~h}$. Representative areas were chosen for ultrathin sectioning and examined with an electron microscope (JEM 1010 transmission electron microscope; JEOL, Peabody, MA, USA) as described previously. Representative digital images were obtained by an AMT imaging system (Advanced Microscopy Techniques, Danvers, MA, USA). Each experiment was conducted in triplicate.

Quantification of acidic vesicular organelles with acridine orange. The cytoplasm and nuclei of acridine orange-stained cells fluoresce bright green and dim red, respectively, whereas acidic compartments fluoresce bright red. ${ }^{39}$ Cells were detached with $0.05 \%$ trypsin-EDTA (Invitrogen) and stained with $1.0 \mu \mathrm{g} / \mathrm{ml}$ acridine orange (Sigma-Aldrich, St. Louis, MO, USA) for $15 \mathrm{~min}$ at room temperature. Stained cells were then analyzed by flow cytometry using the FACScan cytometer (Becton Dickinson, San Jose, CA, USA) and CellQuest software (Becton Dickinson). Each experiment was conducted in triplicate.
Measurement of long-lived protein degradation. Protein degradation was determined using a standard method. ${ }^{40}$ Briefly, T-RexEIG121 (clone A) cells were seeded in 12-well plates and after the cells attached, 0 or $1 \mu \mathrm{g} / \mathrm{ml}$ tetracycline was added to cells for either 8 or $24 \mathrm{~h}$. Cells were then washed and labeled in growth medium containing $0.2 \mu \mathrm{Ci} / \mathrm{ml} \mathrm{L}\left[\left[^{14} \mathrm{C}\right]\right.$ valine (GE Healthcare Life Sciences, Piscataway, NJ, USA) for $24 \mathrm{~h}$. After rinsing three times with PBS, cells were then chased in medium containing $10 \mathrm{mM}$ cold valine for $3 \mathrm{~h}$ to deplete short-lived proteins. After this $3 \mathrm{~h}$ incubation, the medium was discarded and cells were incubated in fresh medium containing $10 \mathrm{mM}$ cold valine for another $16 \mathrm{~h}$. Thereafter, 10\% TCA was used to precipitate protein from the medium, and the radioactivity in the supernatant was determined using a LS6500 Multipurpose Scintillation Counter (Beckman Coulter, Brea, CA, USA). Cells were ruptured in $0.2 \mathrm{M} \mathrm{NaOH}$, and this radioactivity was also determined. Protein degradation was calculated as the percentage of radioactivity in the TCA-soluble supernatant compared with total cell radioactivity (the sum of both the TCA-soluble fraction and radioactivity remaining in the cells). The experiment was repeated three times, and each treatment was performed six times.

Western blotting. Cells were lysed in RIPA buffer containing a cocktail of protease inhibitors (Roche Applied Science), and the cell lysates were cleared by centrifugation at 13000 r.p.m. for $10 \mathrm{~min}$. The proteins $(100 \mu \mathrm{g})$ were resolved in a $12 \%$ SDS-PAGE gel and transferred to a nitrocellulose membrane. Primary antibodies against the LC3 antibody (kindly provided by S. Kondo, M.D. Anderson Cancer Center (3)), EIG121, cleaved caspases 3 and 7, or $\beta$-actin were added to the membrane in $5 \%$ non-fat milk and incubated at $4{ }^{\circ} \mathrm{C}$ overnight. After extensive washing, the membrane was incubated in $5 \%$ non-fat milk containing HRPconjugated anti-rabbit secondary antibody for $30 \mathrm{~min}$ at room temperature. The ECL detection kit (GE Healthcare Life Sciences) was used to visualize the target bands.

RNA interference. EIG121 siRNA duplex GCAAACAGTCCTATACCTA and nontargeting siRNA control were obtained from Dharmacon (Lafayette, CO, USA). When RNAi alone was needed, RNAiMax (Invitrogen) was used for transfection following the manufacturer's protocol, and the combinations of plasmid and siRNA were transfected by Lipofectomine 2000 (Invitrogen). The knockdown efficiency of different concentrations of EIG121 siRNA was tested first; $50 \mathrm{nM}$ was selected, as this concentration provided $88 \%$ reduction of EIG121 mRNA at 24 and $48 \mathrm{~h}$ after transfection, as measured by real-time quantitative RT-PCR.

Statistical analysis. Statistical differences between groups were calculated using the Kruskal-Wallis test. Differences were considered significant if $P<0.05$.

\section{Conflict of interest}

The research work of Dr. Russel Broaddus, Dr. Lei Deng, and J. Feng was funded by $\mathrm{NIH}$. The authors declare no conflict of interest.

Acknowledgements. We thank Dr. S. Kondo at the M.D. Anderson Cancer Center for his advice and for providing us with the LC3 antibody. We also thank Dr. Peter Storz at the Mayo Clinic for providing MDA-MB-231 cells containing pcDNA6/ TR. We are also grateful to Dr. Andrew Bean at the University of Texas Health Science Center at Houston for his advice and for providing us with the M6PR antibody. This work was supported in part by NIH 1P50CA098258-01 (Uterine Cancer SPORE) and NIH 5 T32 HD007324-18 (Training Program in Mammalian Reproduction).

1. Deng L, Broaddus RR, McCampbell A, Shipley GL, Loose DS, Stancel GM et al. Identification of a novel estrogen-regulated gene, EIG121, induced by hormone replacement therapy and differentially expressed in type I and type II endometrial cancer. Clin Cancer Res 2005; 11: 8258-8264.

2. Maxwell GL, Chandramouli GV, Dainty L, Litzi TJ, Berchuck A, Barrett JC et al. Microarray analysis of endometrial carcinomas and mixed mullerian tumors reveals distinct gene expression profiles associated with different histologic types of uterine cancer. Clin Cancer Res 2005; 11: 4056-4066.

3. Mizushima N. Autophagy: process and function. Genes Dev 2007; 21: 2861-2873

4. Mizushima N, Levine B, Cuervo AM, Klionsky DJ. Autophagy fights disease through cellular self-digestion. Nature 2008; 451: 1069-1075.

5. Ohsumi Y. Molecular dissection of autophagy: two ubiquitin-like systems. Nat Rev Mol Cell Biol 2001; 2: 211-216. 
6. Mizushima N. Methods for monitoring autophagy. Int J Biochem Cell Biol 2004; 36 : 2491-2502.

7. Klionsky DJ, Abeliovich H, Agostinis P, Agrawal DK, Aliev G, Askew DS et al. Guidelines for the use and interpretation of assays for monitoring autophagy in higher eukaryotes. Autophagy 2008; 4: 151-175.

8. Tanida I, Minematsu-lkeguchi N, Ueno T, Kominami E. Lysosomal turnover, but not a cellular level, of endogenous LC3 is a marker for autophagy. Autophagy 2005; 1 : 84-91.

9. Sato K, Tsuchihara K, Fujii S, Sugiyama M, Goya T, Atomi Y et al. Autophagy is activated in colorectal cancer cells and contributes to the tolerance to nutrient deprivation. Cancer Res 2007; 67: 9677-9684.

10. Lum JJ, Bauer DE, Kong M, Harris MH, Li C, Lindsten T et al. Growth factor regulation of autophagy and cell survival in the absence of apoptosis. Cell 2005; 120: 237-248.

11. Uchiyama Y, Shibata M, Koike M, Yoshimura K, Sasaki M. Autophagy-physiology and pathophysiology. Histochem Cell Biol 2008; 129: 407-420.

12. Kihara A, Kabeya Y, Ohsumi Y, Yoshimori T. Beclin-phosphatidylinositol 3-kinase complex functions at the trans-Golgi network. EMBO Rep 2001; 2: 330-335.

13. Webber JL, Young AR, Tooze SA. Atg9 trafficking in mammalian cells. Autophagy 2007; 3: 54-56.

14. Young AR, Chan EY, Hu XW, Kochl R, Crawshaw SG, High S et al. Starvation and ULK1dependent cycling of mammalian Atg9 between the TGN and endosomes. J Cell Sci 2006; 119 (Part 18): 3888-3900.

15. Gutierrez MG, Munafo DB, Beron W, Colombo MI. Rab7 is required for the normal progression of the autophagic pathway in mammalian cells. J Cell Sci 2004; 117 (Part 13): 2687-2697.

16. Yamamoto A, Tagawa Y, Yoshimori T, Moriyama Y, Masaki R, Tashiro Y. Bafilomycin A1 prevents maturation of autophagic vacuoles by inhibiting fusion between autophagosomes and lysosomes in rat hepatoma cell line, H-4-II-E cells. Cell Struct Funct 1998; 23: 33-42.

17. Kawai A, Uchiyama H, Takano S, Nakamura N, Ohkuma S. Autophagosome-lysosome fusion depends on the $\mathrm{pH}$ in acidic compartments in $\mathrm{CHO}$ cells. Autophagy 2007; 3: 154-157.

18. Eskelinen EL. Roles of LAMP-1 and LAMP-2 in lysosome biogenesis and autophagy. Mol Aspects Med 2006; 27: 495-502.

19. Settembre C, Fraldi A, Jahreiss L, Spampanato C, Venturi C, Medina D et al. A block of autophagy in lysosomal storage disorders. Hum Mol Genet 2008; 17: 119-129.

20. Liang XH, Jackson S, Seaman M, Brown K, Kempkes B, Hibshoosh $\mathrm{H}$ et al. Induction of autophagy and inhibition of tumorigenesis by beclin 1. Nature 1999; 402: 672-676.

21. Arico S, Petiot A, Bauvy C, Dubbelhuis PF, Meijer AJ, Codogno P et al. The tumor suppressor PTEN positively regulates macroautophagy by inhibiting the phosphatidylinositol 3-kinase/protein kinase B pathway. J Biol Chem 2001; 276: 35243-35246.

22. Crighton D, Wilkinson S, O'Prey J, Syed N, Smith P, Harrison PR et al. DRAM, a p53induced modulator of autophagy, is critical for apoptosis. Cell 2006; 126: 121-134.

23. Ravikumar B, Vacher C, Berger Z, Davies JE, Luo S, Oroz LG et al. Inhibition of mTOR induces autophagy and reduces toxicity of polyglutamine expansions in fly and mouse models of Huntington disease. Nat Genet 2004; 36: 585-595.
24. Abedin MJ, Wang D, McDonnell MA, Lehmann U, Kelekar A. Autophagy delays apoptotic death in breast cancer cells following DNA damage. Cell Death Differ 2007; 14: 500-510.

25. Apel A, Herr I, Schwarz H, Rodemann HP, Mayer A. Blocked autophagy sensitizes resistant carcinoma cells to radiation therapy. Cancer Res 2008; 68: 1485-1494.

26. Vellai T, Bicsak B, Toth ML, Takacs-Vellai K, Kovacs AL. Regulation of cell growth by autophagy. Autophagy 2008; 4: 507-509.

27. Degenhardt K, Mathew R, Beaudoin B, Bray K, Anderson D, Chen G et al. Autophagy promotes tumor cell survival and restricts necrosis, inflammation, and tumorigenesis. Cancer Cell 2006; 10: 51-64.

28. Nelson DA, White E. Exploiting different ways to die. Genes Dev 2004; 18: 1223-1226.

29. Kondo Y, Kondo S. Autophagy and cancer therapy. Autophagy 2006; 2: 85-90.

30. Sun L. Tumor-suppressive and promoting function of transforming growth factor beta. Front Biosci 2004; 9: 1925-1935.

31. Li Y, Guessous F, Kwon S, Kumar M, Ibidapo O, Fuller L et al. PTEN has tumor-promoting properties in the setting of gain-of-mutations. Cancer Res 2008; 68: 1723-1731.

32. Rusten TE, Lindmo K, Juhasz G, Sass M, Seglen PO, Brech A et al. Programmed autophagy in the Drosophila fat body is induced by ecdysone through regulation of the PI3K pathway. Dev Cell 2004; 7: 179-192.

33. Hoyer-Hansen M, Bastholm L, Mathiasen IS, Elling F, Jaattela M. Vitamin D analog EB1089 triggers dramatic lysosomal changes and Beclin 1-mediated autophagic cell death. Cell Death Differ 2005; 12: 1297-1309.

34. Kalamidas SA, Kotoulas OB. Studies on the breakdown of glycogen in the lysosomes: the effects of hydrocortisone. Histol Histopathol 2000; 15: 29-35.

35. Berry DL, Baehrecke EH. Growth arrest and autophagy are required for salivary gland cell degradation in Drosophila. Cell 2007; 131: 1137-1148.

36. Bursch W, Ellinger A, Kienzl H, Torok L, Pandey S, Sikorska M et al. Active cell death induced by the anti-estrogens tamoxifen and $\mathrm{ICl} 164384$ in human mammary carcinoma cells (MCF-7) in culture: the role of autophagy. Carcinogenesis 1996; 17: 1595-1607.

37. Opipari Jr AW, Tan L, Boitano AE, Sorenson DR, Aurora A, Liu JR. Resveratrol-induced autophagocytosis in ovarian cancer cells. Cancer Res 2004; 64: 696-703.

38. Ohshiro K, Rayala SK, Kondo S, Gaur A, Vadlamudi RK, El-Naggar AK et al. Identifying the estrogen receptor coactivator PELP1 in autophagosomes. Cancer Res 2007; 67: 8164-8171.

39. Ito H, Aoki H, Kuhnel F, Kondo Y, Kubicka S, Wirth $\mathrm{T}$ et al. Autophagic cell death of malignant glioma cells induced by a conditionally replicating adenovirus. J Natl Cancer Inst 2006; 98: 625-636.

40. Gronostajski RM, Goldberg AL, Pardee AB. The role of increased proteolysis in the atrophy and arrest of proliferation in serum-deprived fibroblasts. J Cell Physiol 1984; 121: 189-198.

Cell Death and Disease is an open-access journal published by Nature Publishing Group. This article is licensed under a Creative Commons Attribution-Noncommercial-No Derivative Works 3.0 License. To view a copy of this license, visit http:// creativecommons.org/licenses/by-nc-nd/3.0/ 